\title{
PASSAGEM DE PLANTÃO COMO ESTRATÉGIA DE EDUCAÇÃO PERMANENTE EM SAÚDE
}

\author{
Natiele Jorge Santana'; Graziele Alves Flores ${ }^{2}$; Eduarda da Silva \\ Dorneles $^{3}$;Gicelle Moraes Martelli; Pabline Pivetta de Oliveira5; Maclaine de \\ Oliveira Roos ${ }^{6}$; Ticiana Aita Xavier ${ }^{7}$; Regina Gema Santini Costenaro ${ }^{8}$
}

\section{RESUMO}

Objetiva-se neste estudo descrever um relato de experiência, sobre ações de educação permanente durante a passagem de plantão, em uma maternidade, de um hospital público. Foram construídos materiais didáticos do tipo posters, e utilizados como ferramenta para educação permanente. Ocorreram 12 encontros na passagem de plantão, com temas solicitados pelos profissionais da enfermagem. Das discussões deste relato emergiram dois eixos temáticos: evidências científicas como ferramentas que embasam a educação permanente; passagem de plantão como tecnologia didática para a educação permanente. Conclui-se que esta metodologia inovadora de educação permanente, durante a passagem de plantão, contribuiu para instrumentalizar os profissionais e facilitou o acesso ao conhecimento, pois

\footnotetext{
${ }^{1}$ Acadêmica de Enfermagem da Universidade Franciscana - UFN. E-mail: natielesantan@gmail.com

2 Acadêmica de Enfermagem da Universidade Franciscana - UFN. E-mail: flores.graziele8@gmail.com

${ }^{3}$ Acadêmica de Enfermagem da Universidade Franciscana - UFN. E-mail: dorneleseduarda29@gmail.com

${ }^{24}$ Acadêmica de Enfermagem da Universidade Franciscana - UFN. E-mail: gicelle1912@gmail.com

${ }^{5}$ Acadêmica de Enfermagem da Universidade Franciscana - UFN. E-mail: pablinepivetta@gmail.com

${ }^{6}$ Médica. Coordenadora das políticas Primeira Infância Melhor, ISTs/ HIV e Saúde da Criança em Santa Maria-RS. Mestranda em Saúde Materno Infantil da Universidade Franciscana - UFN. E-mail: maclaine@terra.com.br

${ }^{7}$ Médica. Mestranda em Saúde Materno Infantil da Universidade Franciscana - UFN. E-mail: ticiana.xavier@ufn.edu.br

${ }^{8}$ Enfermeira. Doutora em Enfermagem. Docente do curso de Enfermagem da Universidade Franciscana - UFN. E-mail: reginacostenaro@gmail.com
} 
ocorreram no horário de trabalho. Salienta-se a importância das informações que são discutidas na passagem de plantão, a interação entre a equipe, espaço de troca e socialização de saberes, para que a continuidade do cuidado ocorra de maneira efetiva.

Palavras-chave: Enfermagem; Promoção da saúde; Recém-nascido.

Eixo Temático: Atenção Integral e Promoção à Saúde (AIPS).

\section{INTRODUÇÃO}

A Educação Permanente em Saúde reconhece o cotidiano como lugar de invenções, acolhimento de desafios e substituição criativa de modelos por práticas cooperativas, colaborativas, integradas e corajosas na arte de escutar a diversidade e a pluralidade do País. Na proposta da Educação Permanente em Saúde (EPS), a mudança das estratégias de organização e do exercício da atenção, da gestão, da participação ou da formação é construída na prática de equipes, trabalhadores e parceiros, devendo considerar a necessidade de implementar um trabalho relevante, de qualidade e resolutividade. As demandas para qualificação ou especialização são demandas para a promoção de pensamento e ação (BRASIL, 2014).

O período neonatal, compreende os primeiros 28 dias pós-nascimento, é uma fase considerada de extrema vulnerabilidade à saúde do recém-nascido (RN) por estar à mercê de riscos biológicos, ambientais, sociais e culturais. Isso requer cuidados adequados, uma maior vigilância e acompanhamento por parte da equipe multiprofissional de saúde, a fim de garantir um crescimento e desenvolvimento adequados. Esse período é também responsável por $60 \%$ a $70 \%$ dos óbitos neonatais nas últimas décadas, ocorrendo principalmente até o $6^{\circ}$ dia de vida, sendo o indicador fundamental de qualidade da atenção ao recém-nascido (PINHEIRO et al., 2016).

A assistência de enfermagem neonatal é complexa e envolve, além da execução adequada das técnicas de enfermagem, competências do enfermeiro que 
vão desde o conhecimento sobre as patologias mais frequentes, em cada período do desenvolvimento, até as necessidades sociais e emocionais do RN e sua família. Com isso, a atuação da equipe de enfermagem requer um contínuo processo de atualização que demanda um conjunto de estratégias pedagógicas, considerando as demandas e necessidades emergentes do cotidiano do processo de trabalho na unidade neonatal (SILVA et al., 2018).

Este estudo está fundamentado na pesquisa translacional como itinerário de conexão das pesquisadoras com o cenário de prática. Essa conexão instigada pela pesquisa translacional, auxilia o surgimento de tecnologias e de processos didáticos educacionais no dia a dia dos serviços de saúde, por meio da socialização do conhecimento (OLEGÀRIO; VITORINO; SOUZA, 2019; SILVA, et al. 2021).

Dessa forma as ações de promoção, prevenção e assistência à saúde da gestante, puérpera e RN, são de extrema importância, pois influenciam na condição de saúde desde o nascimento até a vida adulta. Cada vez mais, vem sendo salientada a relação determinante entre a vida intrauterina, as condições de saúde no nascimento e no período neonatal, bem como, os problemas crônico-degenerativos na vida adulta, como obesidade, diabetes, doenças cardiovasculares, saúde mental, entre outros (BRASIL, 2014).

Com base no exposto, e considerando que a integração ensino com serviço carece de uma visão ampliada tanto para a formação acadêmica como para a qualificação profissional, a questão norteadora deste estudo é: como a inclusão da formação acadêmica de enfermagem, pode auxiliar nas reflexões e intervenções da prática do cuidado com o RN, utilizando como estratégia EPS na passagem de plantão?

Assim, objetivou-se descrever um relato de experiência sobre as ações de EPS, realizadas, durante a passagem de plantão, na Unidade Santa Isabel (maternidade) do hospital Casa de Saúde em Santa Maria - RS. Descrever a metodologia de construção dos materiais didáticos do tipo posters utilizados como 
ferramenta para a socialização do conhecimento de diferentes situações clínicas que ocorrem no cotidiano da maternidade.

\section{METODOLOGIA}

Trata-se de um estudo descritivo do tipo relato de experiência, desenvolvido por graduandos do curso de enfermagem que cursavam a disciplina de atenção integral à saúde do neonato, criança e adolescente, e mestrandas do mestrado profissional em saúde materna e infantil da Universidade Franciscana- Santa Maria RS. O estudo foi desenvolvido nos meses de maio e junho de 2021 , durante as passagens de plantão das 13 horas, com os profissionais do turno da manhã e da tarde, e as 19 horas com os profissionais da noite. Cada tema foi apresentado e discutido três vezes, e assim conseguiram participar as duas equipes do turno noite. As ações de educação ocorreram na Unidade Santa Isabel- Maternidade, do hospital Casa de Saúde, o qual atende 100\% SUS.

Inicialmente para a realização das capacitações da equipe, foi realizada uma pesquisa científica acerca das patologias que acometem os recém-nascidos, sendo algumas delas: malformações cardíacas, taquipneia transitória, desconforto respiratório e doenças da membrana hialina. A partir do conhecimento adquirido por meio das evidências científicas, foram realizados posters contendo conceitos, sinais e sintomas, fisiopatologias e cuidados de enfermagem. Por meio dos posters, foram apresentadas ilustrações, figuras, gráficos e mapa mental.

Estes posters foram utilizados para socializar o conhecimento com os profissionais da equipe de enfermagem, no término da passagem do plantão, com duração de 15 minutos. Participaram dos encontros 18 profissionais, entre eles: enfermeiras obstetras, técnicos de enfermagem, enfermeiras alunas do programa de residência em enfermagem obstétrica e cinco acadêmicas de enfermagem. Ocorreram no total 12 encontros até o momento, pois estas atividades são permanentes. Este estudo está vinculado ao projeto de mestrado intitulado "Proposta de educação permanente para qualificação do cuidado ao RN na primeira 
semana de vida" é aprovado pelo comitê de ética com número de parecer 4.830 . 591.

Com base no que foi vivenciado, o relato foi será descrito por meio de dois eixos temáticos acerca da experiência em educação permanente em saúde, e material construído para realização da mesma, intitulados: Evidências científicas como ferramentas que embasam a educação permanente; Passagem de plantão como tecnologia didática para a educação permanente.

\section{RESULTADOS E DISCUSSÕES}

\section{1- Evidências científicas como ferramentas que embasam a educação permanente}

Pensando no quanto se faz significativo que os profissionais de saúde permaneçam em constante aprendizado dentro dos cenários de prática, foram desenvolvidos materiais didáticos, posteriormente usados em capacitações na maternidade do hospital Casa de Saúde, citando patologias que poderiam vir a acometer puérperas e recém-nascidos com o intuito de EPS, de modo que os profissionais pudessem relacionar a teoria com a experiência vivenciada por eles no ambiente de trabalho, e relembrar casos clínicos pouco evidentes dentro dos cenários de prática.

Primeiramente foi desenvolvida uma pesquisa a respeito dos seguintes temas: Hemorragia Obstétrica, Cardiopatias Congênitas, Taquipneia transitória, Desconforto Respiratório, e a partir dos achados científicos foi desenvolvido um pôster com os conhecimentos adquiridos através da revisão na literatura.

A hemorragia pós-parto pode ser definida como a perda sanguínea maior que $500 \mathrm{ml}$ no pós-parto vaginal ou maior que $1000 \mathrm{ml}$ na cesariana. Contudo, o mais importante é considerar que qualquer perda sanguínea capaz de causar instabilidade hemodinâmica deve ser considerada como um caso de hemorragia 
pós-parto importante. A maioria dos casos de morte materna por hemorragia pós-parto pode ser evitável, reduzindo assim as estatísticas, e colocando em prática as condutas adequadas de complexidade variável, propostas desde o pré-natal até o período puerperal. O tratamento da hemorragia não deve ser o único objetivo das discussões sobre o tema, mas também as estratégias de prevenção das hemorragias (FIOCRUZ, 2019).

As cardiopatias congênitas são anomalias ocasionadas por defeitos anatômicos do coração ou dos grandes vasos associados, os quais produzem insuficiência circulatória e respiratória dentre outras consequências graves, podendo comprometer a qualidade de vida ou a própria vida do paciente. De acordo com o Ministério, "o acompanhamento médico no pré-natal é importante para o diagnóstico, caso existam fatores que levantem a suspeita clínica de problemas cardíacos-fetais. O ultrassom morfológico também pode apontar indícios de cardiopatia. Tem ainda o teste de coraçãozinho realizado antes da alta hospitalar, entre 24 e 48 horas após o nascimento" (FIOCRUZ, 2020).

A Síndrome do Desconforto Respiratório é a afecção respiratória mais frequente no RN pré-termo, sendo mais comum nos RN prematuros com menos de 28 semanas de gestação, do sexo masculino, em filhos de mãe diabética e nos que sofreram asfixia ao nascimento. O RN pré-termo com idade gestacional inferior a 35 semanas apresenta, portanto, deficiência da quantidade total de surfactante pulmonar. Tal deficiência resulta em aumento da tensão superficial e da força de retração elástica, levando à instabilidade alveolar com formação de atelectasias progressivas, com diminuição na complacência pulmonar e na CRF (BRASIL, 2012).

A Taquipneia Transitória do RN ou síndrome do pulmão úmido é caracterizada por um desconforto respiratório leve a moderado, geralmente de evolução benigna, decorrente de retardo na absorção do líquido pulmonar após o nascimento. Durante o processo de nascimento ocorrem alterações cardiopulmonares importantes. Cessa a produção e secreção do líquido pulmonar, que é substituído por ar. A absorção do líquido pulmonar inicia-se antes do nascimento, com o início do trabalho de parto, 
por mecanismos ainda pouco conhecidos. Estima-se que cerca de $70 \%$ do líquido seja reabsorvido antes do nascimento. Durante a passagem pelo canal de parto, são eliminados cerca de $5 \%$ a $10 \%$ do líquido pulmonar e o restante é absorvido nas primeiras horas de vida pelos vasos linfáticos e capilares pulmonares (BRASIL, 2012)

\section{2 - Passagem de plantão como tecnologia didática para a educação permanente}

Após a busca por referenciais teóricos e o desenvolvimento dos materiais didáticos, foi apresentado para a equipe a proposta de EPS para ser operacionalizada ao término da passagem de plantão, sendo utilizada este momento, como estratégia, pois todos estariam reunidos na sala de Enfermagem. Os encontros aconteceram nos horários, de trocas de plantão, das 13 horas e das 19 horas, tendo duração de 15 minutos, sendo que cada tema foi repetido três vezes, e ao todo foram apresentados seis temas, totalizando 18 encontros até o momento, pois a EPS continua ocorrendo.

Durante todo o período dos encontros, percebeu-se o envolvimento da equipe, relatando suas experiências acerca dos casos apresentados, fazendo questionamentos, e mostrando interesse pelos temas. Sabe-se que, conciliar trabalho com a vida pessoal, demanda estratégias de administração do tempo, o que dificulta, muitas vezes, que o profissional consiga se dedicar aos estudos ou leituras que possam instrumentalizar as atividades de cuidados que se apresentam no cenário de prática. Por este motivo, a proposta de EPS na passagem de plantão, facilita a participação dos profissionais nos encontros, integra a equipe no cenário de prática, e mantém os mesmos atualizados sobre os cuidados de enfermagem.

É evidente o interesse dos profissionais pelo aprender, principalmente quando esse conhecimento é levado a eles de uma forma leve, com exemplos claros e troca de saberes entre a equipe, e é justamente pelo fato de ver essa vontade de 
aprender que percebo como fator desafiador o modo como eles estão acomodados. Por estarem no ambiente de trabalho, iniciando ou terminando seus turnos, nem sempre conseguirão estar $100 \%$ presentes naquele ambiente, ou seja, concentrados no conhecimento que Ihes está sendo transmitido. É uma medicação para a dor que precisa ser administrada logo, é um parto que está acontecendo naquele momento, é um familiar que necessita da tua atenção, então por muitas vezes alguns não estarão atentos e centrados no propósito.

Em contrapartida acompanhar a iniciativa da EPS durante as passagens de plantão, e observar o modo como os profissionais reagiram a mesma, me trouxe reflexões acerca do quanto é válido que os acadêmicos/ residentes/ mestrandos e demais profissionais que ainda estejam inseridos dentro das instituições de ensino, consigam transmitir conhecimento aos profissionais que já estão atuando e carecem de estar em constante atualização dos seus cuidados.

A troca de conhecimento entre teoria e prática, dá origem a translação do conhecimento conectando as necessidades da prática com o saber científico contemporâneo, instigando um diálogo os aproximou-se das necessidades científicas atuais, proporcionando o diálogo entre as ciências (OLEGÀRIO; VITORINO; SOUZA, 2019). A partir desta experiência, que a pesquisa translacional, auxilia na integração ensino-serviço-ensino, adicionado a estratégia de ocorrer na passagem de plantão, momento em que todos estão atentos, num espaço que lhe é familiar, um método receptivo e seguro, que aproxima a equipe e qualifica os cuidados de enfermagem com o RN.

\section{CONCLUSÃO}

Mediante o exposto, se fortalece a ideia de que a EPS é necessária devido a constante demanda de novas tecnologias e condutas farmacológicas, bem como patologias que se apresentam de várias especificidades. As discussões e reflexões que surgem no cenário profissional, favorecem a socialização de conhecimentos, bem como, trazem mais segurança para a realização dos cuidados de saúde. 
As discussões de EPS potencializaram o vínculo entre a equipe de formação acadêmica (graduação e mestrado), pelo fato de estar aprendendo na prática e os profissionais da prática, pela ocasião de instrumentalizar seu fazer profissional, e os recém-nascidos e puérperas pela qualidade do cuidado recebido. $O$ momento de passagem de plantão foi benéfico, pois favoreceu os profissionais no horário de trabalho e trouxe discussões atuais e de acordo com o vivido, resultando em sentimento de satisfação e gratidão dos participantes.

\section{REFERÊNCIAS}

BRASIL. Ministério da Saúde. Atenção a Saúde do Recém-nascido. Cuidados gerais, $\quad$ v.1, $\quad 2^{\circ} \quad$ edição, $2014 . \quad$ Disponível em: https://bvsms.saude.gov.br/bvs/publicacoes/atencao_saude_recem_nascido_v1.pdf. Acesso em: 13/09/202.

BRASIL. Ministério da Saúde. Atenção a Saúde do Recém-nascido. Problemas circulatórios, cardiocirculatórios, metabólicos, neurológicos, ortopédicos e dermatológicos, v.3, $2^{\circ}$ edição, 2012. Disponível em: https://bvsms.saude.gov.br/bvs/publicacoes/atencao_saude_recem_nascido_profissi onais_v3.pdf. Acesso em: 16/09/2021.

BRASIL. Ministério da Saúde. Educação Permanente em Saúde. Reconhecer a produção local de cotidianos de saúde e ativar práticas colaborativas de aprendizagem e de entrelaçamento de saberes, 2014. Disponível em: https://bvsms.saude.gov.br/bvs/folder/educacao_permanente_saude.pdf. Acesso em: 13/09/2021. 
FIOCRUZ. Ministério alerta para o diagnóstico precoce de cardiopatia congênita entre crianças.

Disponível em:https://www.bio.fiocruz.br/index.php/br/noticias/1831-ministerio-alerta-para-o-diag nostico-precoce-de-cardiopatia-congenita-entre-as-criancas. Acesso em: $16 / 09 / 2021$.

OLEGÁRIO, R.L.; VITORINO, S.M.A.; SOUZA, P.V.N. de. Pesquisa translacional do ensino superior no campo das ciências da saúde. RIR [Internet]. 2019 [acesso em 12 dez 2019]; 15(2). Disponível em: https://revistas.ufg. br/rir/article/view/56988.

PINHEIRO et al;: Atenção à criança no período neonatal: avaliação do pacto de redução da mortalidade neonatal no Rio Grande do Norte, Brasil. Ciência \& Saúde Coletiva, v.21, $\mathrm{n}^{0} .1, \quad$ pg:243-252, 2016. Disponível em: https://www.scielo.br/j/csc/a/Tc3qSNwgnbLQx3NPzrkbZxK/?lang=pt. Acesso em: $13 / 09 / 2021$.

FIOCRUZ. Portal de boas práticas em saúde da mulher, da criança e do adolescente. Principais questões sobre manejo da hemorragia no pós-parto. Disponível em: https://portaldeboaspraticas.iff.fiocruz.br/atencao-mulher/principais-questoes-sobremanejo-da-hemorragia-no-pos-parto/. Acesso em: 16/09/2021.

SILVA et al;. Educação permanente em unidade neonatal a partir de círculos de cultura. Rev Bras Enferm, v.71, $\mathrm{n}^{0} 3$, pg:1408-14, 2018. Disponível em: https://www.scielo.br/j/reben/a/kMjHRTCqzzSMGmbnxQqX9qG/?lang=pt\&format=ht ml. Acesso em: 13/09/2021. 


\section{QSUFN}

SILVA, V.B. da; MENDES, V.A.; LIMA, S.C.F. de; GONÇALVES, T.L.P.; PAES, G.O.; STIPP, M.A.C. Educação permanente na prática da enfermagem: integração entre ensino e serviço. Revista Cogitare enferm. 2021, v26:e71890 